Где-то около года назад мы пришли к общению на ты. Наверное, это было правильно и естественно, хотя мы и принадлежали к разным поколениям, но нас многое сближало, и прежде всего профессия, а если говорить конкретнее, - глобалистика как наука.

Не думал, что мне придется писать этот текст. Да, не стало Олега Николаевича Яницкого - архитектора, художника, доктора, профессора, автора десятков монографий и сотен статей, блестящего оратора, который свободно читал лекции на английском на далеком Западе и работал в ЮНЕСКО. Подробно об этом можно посмотреть в Интернете. Я хочу сказать о другом, вспоминая близкого мне человека.

Он ушел неожиданно быстро, словно не хотел никого обременять своей немощью. Я несколько раз пытался его навестить дома. Но он все откладывал и откладывал мой приход. Очевидно, не случайно. Как человек полностью сохранивший свой мозг до конца, он не хотел, чтобы видели его слабость.

Мы сблизились с ним на проблемах современной глобалистики, таких как цифровизация, сетевое общество, новые коммуникации, человек, общество и государство во всем этом. Он поразительно остро чувствовал новейшие экзистенциальные процессы нашей жизни, причем его глубокое гуманитарное видение позволяло ему уйти от узко технократического, утилитаристского подхода. Он всегда отстаивал междисциплинарный подход к проблемам. Он был настоящим социологом - гуманитарием, стремящимся за суетой научной повседневности и нарочитой бюрократизацией увидеть болезненные симптомы современного общества вообще и российского в частности. Он был аристократом интеллекта и духа, никогда не позволял входить к себе с черного хода. Сейчас таких становится все меньше и меныше. Общество потребления и современные коммуникации захлестнули индивидуальную составляющую современной жизни.

Он никогда не был ретроградом, его мозг всегда работал на будущее. В своих исследованиях он старался осмыслить и просчитать те вызовы и риски, которые со всей очевидностью возникли в начале XXI века. Гуманистическая составляющая в самой высокой ее основе всегда имплицитно входила в его экспертные и аналитические разработки. Он был настоящим эрудитом и обладал энциклопедическими знаниями по темам, которые входили в круг его интересов. А еще у него был очень острый, абсолютно самодостаточный характер. Я таких называю человек-формация...

Спасибо тебе, дорогой Олег, за все-все. Я и мы - редакция - будем всегда тебя чтить, помнить и цитировать. 
ЯНИЦКИЙ Олег Николаевич - доктор философии, профессор; главный научный сотрудник Института социологии Федерального научно-исследовательского социологического центра РАН (117218, Россия, г. Москва, ул. Кржижановского, 24/35, корп. 5; oleg.yanitsky@yandex.ru)

\title{
ЧЕТВЕРТАЯ НАУЧНО-ТЕХНИЧЕСКАЯ РЕВОЛЮЦИЯ И КУЛЬТУРА В КОНТЕКСТЕ ПАНДЕМИИ
}

\begin{abstract}
Аннотация. Статья посвящена актуальной сегодня проблеме соотношения технонауки и культуры как общего достояния человечества. Они, имея общие корни в человеческом мастерстве и изобретательности в четвертой индустриальной революции (далее - НTP-4), стали все более расходиться. Конструирование всегда было более легким и увлекательным занятием, чем познание закономерностей эволюции биосферы и развития человечества. Однако сегодня обособленное рассмотрение этих двух сфер глобальной активности достигло своего предела, что продемонстрировала пандемия и ее экономические и социальные последствия. Системность, междисциплинарный подход, метаболические процессы быстро перестают быть сугубо научными понятиями, трансформируясь в базовые принципы глобального культурного процесса.
\end{abstract}

Ключевые слова: время, глобализация, информационная система «Галактика», культура, научно-техническая революция, технический язык, технонаука, человечество, эволюция

\section{Постановка проблемы}

В чем заключается специфика современной глобальной динамики? Если до сих пор ее развитие шло в ритме «экономический кризис, его преодоление, затем снова кризис», то сегодня, во-первых, речь идет не только об экономическом кризисе, но о системной критической ситуации, охватившей практически весь земной шар. И эта критическая ситуация продолжает эволюционировать, причем о ее цикличности говорить не приходится. Конструирование всегда было относительно более легким и увлекательным занятием, чем познание закономерностей эволюции биосферы и человечества. Однако сегодня обособленное рассмотрение этих двух сфер глобальной активности достигло своего предела, что продемонстрировала пандемия и ее экономические и социальные последствия. И, как отмечал еще Ю. Давыдов, речь идет не о выходе из очередного кризиса, а о его перерождении [Давыдов 1998: 4], т.е., в моем понимании, о его трансформации в глобальное критическое состояние.

Казалось бы, эти трансформации не имеют никакого отношения к проблеме соотношения технонауки и культуры. Но обратимся сначала к истории. Кирилл и Мефодий (IX в. н. э.), а позже Гуттенберг (XV в. н. э.) создали славянскую и западноевропейскую письменность (азбуку и способ книгопечатания), дав тем самым науке и практике некоторые общие правила речи, правописания, а также накопления и распространения знаний. Эти способы оказали огромное влияние на развитие человеческой культуры, науки, производства и образования. Однако эти просветители никогда не покушались на какую-либо унификацию социально-экономических отношений в европейских и славянских государствах и, тем более, на унификацию человеческой культуры. Их основная заслуга состояла в создании материальной основы для названных выше форм человеческой деятельности. Однако сам этот факт можно расценивать как явление культуры.

Однако создатели информационной системы «Галактика» претендуют на гораздо большее. Они имеют цель перевести все виды и формы человеческой 
коммуникации на единый, постоянно развивающийся технологический язык. Иначе говоря, речь идет о глобальной унификации форм и способов социального и культурного бытия человечества, что, по существу, исключает разнообразие человеческих культур.

В основе этого процесса лежат экономические причины (свойства) жизнедеятельности современного человечества, где главным мерилом любой социальной деятельности является прибыль (выгода, победа над вероятным противником и т.п.). Не случайно даже время, эта, казалось бы, универсальная категория, приобрела вполне осязаемую цену («время - деньги», гласит известная поговорка). И тем более, не случайно именно английский язык (в его наиболее упрощенной, унифицированной форме, так называемый Basic English) стал тем «мировым языком», который сегодня господствует в глобальной экономике и политике.

Более того, этот «технический английский язык» вполне соответствует требованиям современной технонауки, стремящейся уложить в прокрустово ложе технократической идеологии все многообразие культур, представлений и жизненных укладов современного мира. Несомненно, что технократическая идеология стремится упростить и унифицировать весь мир в соответствии с вышеназванными принципами глобального капитализма, но борьба между ним и национально-культурными общностями еще далеко не окончена. И пандемия привела скорее к усилению стремления к национально-культурной самобытности наций или их сообществ, нежели к их унификации и тотальной «дигитализации».

\section{Специфика современной ситуации}

То есть, мир сегодня охвачен двуединым процессом «интеграции - автономизации», и, как мне представляется, это его нормальное диалектическое состояние. Причем оно не только нормальное, но, вероятно, единственно возможное, поскольку оно позволяет, с одной стороны, поддерживать глобальный обмен людьми, товарами и знаниями, а с другой - сохранять специфику культур стран и народов. С моей точки зрения, это нормальный «колебательный» процесс, в котором есть моменты расширения и сжатия, ускорения и замедления, а также постоянного обмена людьми и ресурсами, т.е. эти процессы сродни тем, что происходят в природных экосистемах.

Далее, между национальными культурами и унифицированной технокультурой и, соответственно, между национальными и «техническими» языками существует принципиальное различие. Первые порождаются народностями и нациями и затем поддерживаются, воспроизводятся именно ими, тогда как вторая работает на унификацию окружающего нас социального мира, людей, их образа жизни, вещей, средств коммуникации и транспорта и т.д., и т.п.

Однако парадокс в том, что чем геополитически мощнее становится технокультура, тем слабее ее устойчивость и меньше ее разнообразие. А именно разнообразие является залогом устойчивость экосистемы Земли. Не зря существует поговорка: «Что написано пером, того не вырубишь топором». Этот принцип можно выразить иначе: никакие выставки технических новинок, художественные вернисажи или спортивные зрелища не могут заменить человеческого общения, что наглядно продемонстрировала пандемия коронавиpyca.

В техноязыке есть свое разнообразие, но оно чаще всего построено по арифметическому принципу: «да - нет, ближе - дальше, сильнее - слабее, более или менее прочно» и т.П. Но этот язык может давать лишь калейдоскоп «картинок», чем грешит телевидение, особенно реклама, но он не может выражать 
или отражать множество эмоциональных состояний человека, его чувств, переживаний и тому подобных сложных психоэмоциональных реакций. И в этом случае постоянное ускорение смены «картинок» может лишь демобилизовать реципиента, вести к его отупению. Так что технологические ухищрения в передаче (трансляции) сложных и быстро развивающихся ситуаций может привести лишь к обратному результату: индивид теряет способность к осмыслению происходящего на экране телевизора или смартфона.

Недостатки и пределы возможностей «технологических языков» легко увидеть на примере возможностей и результатов машинного перевода. Как отмечалось выше, суть вашего текста (статьи или книги), чаще всего (но далеко не всегда!) будет переведена правильно, но все интонации автора или его акценты на тех или иных положениях его рукописи будут утеряны.

Специалисты по применению «технологических языков» к современным критическим ситуациям сталкиваются с большими трудностями, когда речь идет не о единовременных, одномерных и четко локализуемых событиях (авариях, катастрофах), а о длительных и качественно трансформирующихся цепях критических событий (я их называю каскадными). Такие события очень сложно моделировать не только технологически, но также потому, что информацию о них никто систематически не собирает или тщательно скрывает, или же тот, кто собирается строить модели каскадных процессов, не в состоянии собрать релевантную информацию ввиду сложности и непредсказуемости развития конкретного каскадного процесса.

Если при этом учесть необходимость моделирования метаболических трансформаций [Яницкий 2013], которые могут происходить в самых разных средах или между ними (например, между загрязнением воды химикатами и его воздействием на донные отложения, на множество микроорганизмов и т.д.), то задача становится практически неразрешимой. К тому же, как показывает мировая практика, власти пытаются скрыть истинные причины, характер и масштаб конкретной катастрофы. Иными словами, «интересы» природных экосистем приходят в столкновение с экономическими и политическими интересами системы «власть - собственность». Характерно, что в обыденном языке метаболические процессы уже давно нашли свое отражение, например, в таких словах, как сплав, металлизированная пластмасса и многих других. В сфере науки, и тем более в технонауке, этот процесс осознания сложности, системности современного мира только начинается.

\section{НТР-4 и сфера культуры}

Сфера культуры, понимаемая здесь достаточно широко, сегодня находится под непрерывным воздействием ускоряющихся перемен, создаваемых НТР-4. Мы привыкли понимать культуру как нечто абсолютное, неизменное, т.е. как важный ориентир в этой быстротекущей жизни. Между тем разрыв между динамикой быстротекущих перемен и статикой культурных основ социальной жизни все более увеличивается. НТР-4 и ее апологеты создают совершенно иной тип культуры - культуры непрерывно ускоряющейся и изменяющейся, т.е. они являются создателями «культуры момента» и СМИ как инструмента ее воспроизводства.

У русской культуры XIX-XX вв. (Ф. Достоевский, Л. Толстой, А. Чехов и многие другие) всегда существовала общая нравственная основа. Сегодня же, по моему мнению, эта зависимость поставлена с ног на голову: эти основы каждый раз создаются заново быстротекущими потребностями массового общества. В известном смысле сегодня повторяется картина поздней Римской империи, когда драйвером культуры был принцип: «хлеба и зрелищ», со- 
здаваемый этим массовым обществом, причем стереотипы зрелищ все чаще заимствуются у массовой культуры Запада. Эти «культурные образцы» быстро возникают и столь же быстро исчезают. Таким образом, не великие писатели, философы и художники создают фундаментальные ценности нашей жизни, а массовое общество, а точнее - его элита.

Инструментом воспроизводства непрерывно меняющейся массовой культуры является система массовых коммуникаций. Напомню, что «массовое общество» - это не масса людей, а система социальных институтов, формирующих потребности этого общества. И эти институты - плоть и кровь современного индивидуалистического общества, которые приносят немалый доход. Без них стереотипы массовой культуры никогда бы так быстро не создавались и столь же быстро не исчезали бы с публичной арены общества. Но есть и более глубокая и объективная причина такой перемены: вытеснение вечных ценностей добра, взаимопомощи и взаимопонимания сиюминутными поведенческими образцами, которые непрерывно конструируются в недрах института массовой культуры. Приходится признать, что прибыль или, выражаясь словами К. Маркса, «чистоган», является главной движущей силой массовой культуры.

Поэтому необходимо четко разграничивать феномен массовой культуры и информации, необходимой для принятия решений. Вот простой и всем известный пример. Когда случается некоторая критическая ситуация или катастрофа, система массовых коммуникаций резко сокращает свой «развлекательный» потенциал и переориентируется на мобилизацию сил и средств данного общества для отражения внезапного нападения противника или для быстрейшей ликвидации негативных последствий случившейся катастрофы.

Замечу, что такая мобилизационная ситуация, когда одновременно требуется переосмысление недавнего прошлого и текущего настоящего плюс прогнозирование ближайшего и более отдаленного будущего, плюс ориентация данного общества в быстро меняющемся социальном пространстве, - задача не для искусственного интеллекта, по крайней мере, в ближайшем будущем. И вот здесь возникает фундаментальная задача современной культуры: как в критических условиях (пандемия или другое массовое бедствие) одновременно сохранить наши фундаментальные ценности (устои, скрепы) и переориентировать общественное сознание на решение таких непростых задач, как пандемия и ее последствия. Причем эта задача носит «процессуальный», т.е. опять же системный, характер, поскольку, как показала практика, при пандемии ужесточение самоизоляции дает положительный результат, а небольшое ослабление этого режима снова дает рост заболеваемости.

Я не знаю, будет ли когда-нибудь создан «глобальный коллективный искусственный интеллект», но ситуация с пандемией и другими авариями и катастрофами мирового масштаба четко показала, что диалог или дискуссия профессионалов (экспертов) пока что дает гораздо более быстрые и социально значимые результаты, нежели технически сконструированные модели искусственного интеллекта. С моей точки зрения, в обозримой перспективе этот интеллект, несомненно, будет служить подспорьем в решении сложных, но пока что частных задач. Но, теоретически говоря, создание «глобального коллективного искусственного интеллекта» возможно только в случае, когда мировое сообщество осознает пагубность борьбы на всеобщее взаимное уничтожение, т.е. когда это сообщество сможет выработать общие для всех малых и больших народов правила мирного общежития.

Есть еще одно существенное теоретическое соображение: непрерывное ускорение развития человеческого общества, стимулируемое развитием техноло- 
гий, имеет свои пределы. Эти пределы имеют, по крайней мере сегодня, двойственный характер: внутренние и внешние. Внутренние пределы - это пределы, детерминируемые возможностями человеческой рефлексии, т.е. необходимыми для этого теоретическими и эмпирическими знаниями и временем на размышления. Сегодня человек не хочет уподобляться машине, совершающей просто перебор возможных вариантов решения некоторой проблемы. Человек хочет думать, размышлять, и информационные технологии для него - лишь инструмент, облегчающий мыслительный процесс. Если человечество откажется думать, то это закончится крахом этой цивилизации.

\section{О необходимости системного мышления}

Внешние пределы, т.е. состояние и динамика глобальной экосистемы, всегда были и будут ограничителями этого мыслительного процесса и принятия любых решений. Сегодня не только отдельный человек, но и человечество в целом постепенно приходят к необходимости мыслить системно, т.е. экологически. Иными словами, уже в недалеком будущем на смену «частичным» решениям придут именно экосистемные решения. И это не плод досужей фантазии, а фундаментальный принцип мироздания, в котором живет современное человечество. Но именно этот тезис находится в явном противоречии с принципом «чистогана», который, как показала та же пандемия, все же придется как-то преодолевать или реформировать.

Как именно преодолевать - это тема отдельного исследования. Когда-то известный теоретик глобализации У. Бек сказал, что многие человеческие несчастья (the bads, в его терминологии) имеют свою позитивную сторону, т.к. они заставляют людей переосмысливать фундаментальные принципы культуры и организации капиталистического общества [Beck 1999]. Но еще не закончившаяся пандемия уже четко показала, в каком именно направлении человечество должно двигаться: например, к более открытому и своевременному обмену актуальной информацией, к некоторым общим принципам подготовки к экстремальным ситуациям и т.д. Но главное, на мой взгляд, это необходимость все более глубокого осознания того факта, что всякая научнотехническая революция имеет свои теневые и просто отрицательные стороны. Или, иначе, что теоретические основы технонауки и культуры всего человечества не должны противоречить друг другу.

Однако каковы культурные основания технонауки? Пока серьезных разработок на этом направлении я не вижу. До сих пор, по крайней мере в отношении человека и его уклада жизни, происходило несанкционированное вмешательство технонауки сначала в личную жизнь (я имею в виду непрерывные хакерские атаки с самыми разными целями - ограбление, получение информации об укладе жизни конкретного человека и его семьи), а позже это уже перешло в непосредственное вмешательство в интимную жизнь (насильственное разрушение института семьи посредством ликвидации половых различий), а также такое же вмешательство в воспитательный процесс в детском саду, школе и т.д.

Но отступим несколько назад, в города и их среду обитания XVI-XIX вв., которые нас так привлекают не только как туристов, но и как любителей старины, и как средство познания окружающего нас мира. Однако уже почти 100 лет назад известный французский архитектор Ле Корбюзье, будучи участником международной дискуссии о путях создания социалистического города будущего в Советском Союзе, предлагал снести всю старую Москву (за исключением нескольких исторически значимых комплексов и построек, например, Московского Кремля), превратив ее в огромный парк с отдельно стоящими жилыми домами-небоскребами. Более того, он уже тогда утверждал, что «дом - 
это машина для жилья». Иными словами, Ле Корбюзье предлагал отрезать, отрубить всю историческую память нашего общества.

Поэтому я полагаю, что технонаука в широком смысле этого слова - как конструктивистский уклон в социальной деятельности - страдает сегодня своеобразной болезнью памяти, только наоборот. Оперативная память, т.е. реакция на быстротекущие изменения, у нее существует и быстро развивается, а фундаментальная историческая память о близком и более отдаленном прошлом, т.е. то, что мы называем всемирной и российской историей и, соответственно, фундаментальными ценностями, осталась на уровне учебника для 5-6-го классов средней школы.

Поэтому я предлагал трактовать современное состояние биосферы как социобиотехносферу [Яницкий 2016], в которой все виды и формы природной и социальной активности тесно взаимосвязаны. Обособление научных дисциплин, заложенное в XVII в. отцами-основателями Просвещения, сегодня должно быть преодолено.

\section{Выводы}

Технические науки и новые технологии, несомненно, нужны и будут развиваться, однако чем далее, тем более они будут становиться междисциплинарными инструментами - сферами знания-действия, отражающими интегрированный характер системы «общество - природа». Соответственно, накопленный веками пласт человеческой культуры не должен вытесняться или подменяться технонаукой. Напротив, человеческая культура должна осваивать ее в присущих ей ментальных и визуальных формах. Возникает необходимость развития экосистемного и междисциплинарного подходов к динамике планеты и ее обитателей и освоения этого процесса в терминах общечеловеческой и национальной культуры. Системность, междисциплинарный подход, метаболические процессы быстро перестают быть сугубо научными понятиями, трансформируясь в базовые принципы глобального культурного процесса.

\section{Список литературы}

Давыдов Ю.Н. 1998. «Новый русский» капитализм в свете кондратьевского понимания эволюции. М.: Международный фонд Н.Д. Кондратьева. 30 с.

Яницкий О.Н. 2013. Метаболическая концепция современного города. Социологическая наука и социальная практика. Т. 2. № 3. С. 16-32.

Яницкий О.Н. 2016. Социобиотехнические системы: новый взгляд на взаимодействие человека и природы. - Социологическая наука и социальная практика. Т. 4. № 3. С. 5-22.

Beck U. 1999. World Risk Society. Malden, MA: Polity Press. 184 p. 